OPEN ACCESS

Edited by:

Stefano Biressi,

University of Trento, Italy

Reviewed by:

Marco Quarta

Stanford University, United States

Tomohiro Nakamura,

Osaka Institute of Technology, Japan

${ }^{*}$ Correspondence:

Mark P. Lewis

m.p.lewis@lboro.ac.uk

Vivek Mudera

v.mudera@ucl.ac.uk

${ }^{+}$Co-senior authors

Specialty section: This article was submitted to Striated Muscle Physiology, a section of the journal

Frontiers in Physiology

Received: 09 January 2018 Accepted: 16 April 2018

Published: 08 May 2018

Citation:

Jones JM, Player DJ, Martin NRW, Capel AJ, Lewis MP and Mudera V (2018) An Assessment of Myotube Morphology, Matrix Deformation, and Myogenic mRNA Expression in Custom-Built and Commercially Available Engineered Muscle Chamber Configurations. Front. Physiol. 9:483. doi: 10.3389/fphys.2018.00483

\section{An Assessment of Myotube Morphology, Matrix Deformation, and Myogenic mRNA Expression in Custom-Built and Commercially Available Engineered Muscle Chamber Configurations}

Julia M. Jones ${ }^{1,2}$, Darren J. Player ${ }^{1,2}$, Neil R. W. Martin², Andrew J. Capel'2, Mark P. Lewis ${ }^{2 *+}$ and Vivek Mudera ${ }^{1 *+}$

\footnotetext{
${ }^{1}$ Division of Surgery and Interventional Science, Institute of Orthopaedics and Musculoskeletal Science, University College London, London, United Kingdom, ${ }^{2}$ School of Sport, Exercise and Health Sciences, Loughborough University, Loughborough, United Kingdom
}

There are several three-dimensional (3D) skeletal muscle (SkM) tissue engineered models reported in the literature. 3D SkM tissue engineering (TE) aims to recapitulate the structure and function of native (in vivo) tissue, within an in vitro environment. This requires the differentiation of myoblasts into aligned multinucleated myotubes surrounded by a biologically representative extracellular matrix (ECM). In the present work, a new commercially available 3D SkM TE culture chamber manufactured from polyether ether ketone (PEEK) that facilitates suitable development of these myotubes is presented. To assess the outcomes of the myotubes within these constructs, morphological, gene expression, and ECM remodeling parameters were compared against a previously published custom-built model. No significant differences were observed in the morphological and gene expression measures between the newly introduced and the established construct configuration, suggesting biological reproducibility irrespective of manufacturing process. However, TE SkM fabricated using the commercially available PEEK chambers displayed reduced variability in both construct attachment and matrix deformation, likely due to increased reproducibility within the manufacturing process. The mechanical differences between systems may also have contributed to such differences, however, investigation of these variables was beyond the scope of the investigation. Though more expensive than the custombuilt models, these PEEK chambers are also suitable for multiple use after autoclaving. As such this would support its use over the previously published handmade culture chamber system, particularly when seeking to develop higher-throughput systems or when experimental cost is not a factor.

Keywords: skeletal muscle, tissue engineering, $\mathbf{C 2 C 1 2}$, myotubes, commercially available muscle chamber, custom-built muscle chamber 


\section{INTRODUCTION}

Tissue engineered (TE) three-dimensional (3D) constructs allow for complex representation of several tissue types in vitro, including skeletal muscle (SkM). The goal of 3D SkM TE is to emulate native muscle (Ostrovidov et al., 2014; Perniconi and Coletti, 2014; Khodabukus and Baar, 2015), which includes the geometrical, topographical, and physical features of the targeted tissue (Mohanty et al., 2015). Native SkM tissue consists of parallel arrays of multinucleated myofibers of relatively equal size (Bian and Bursac, 2008; Riboldi et al., 2008; Gillies and Lieber, 2011) that are surrounded by an extracellular matrix (ECM; Gillies and Lieber, 2011). Therefore, a requirement of SkM TE is the development of uniaxially aligned myotubes, typically achieved utilizing a high cell density of muscle precursor cells, seeded on or within a scaffold anchored between two secured fixed points (Sakar et al., 2012).

Several published TE 3D SkM models have been reported in the literature, for example, cylindrical (Okano and Matsuda, 1998; Vandenburgh et al., 2008), mandrel/cylindrical (Okano and Matsuda, 1997), tubular (Huang et al., 2005; Khodabukus and Baar, 2009; Martin et al., 2015), and rectangular/cuboidal systems have been previously demonstrated (Eastwood et al., 1996; Cheema et al., 2003, 2005; Mudera et al., 2010; Smith et al., 2012; Hodgson, 2015; key features summarized in Table 1). Whilst these models (regardless of geometry or size) represent simplified versions of the desired complex tissue, 3D SkM constructs have been shown to be capable of supporting cell growth and maturation (Cen et al., 2008; Bian and Bursac, 2009), force production (Powell et al., 2002; Ito et al., 2014), and supporting co-culture with organotypic cell types such as motor neurons (Morimoto et al., 2013; Martin et al., 2015; Smith et al., 2016).

These 3D TE SkM models are typically cultured within chambers, which are fabricated using bespoke techniques and/or custom designs. As such, a large number of models exist (Vandenburgh et al., 1996, 2008; Dennis and Kosnik, 2000; Powell et al., 2002; Cheema et al., 2003, 2005; Chiron et al., 2012; Snyman et al., 2013; to list a few, summarized in Table 1). Thus, manufacturing reproducible chambers can be problematic, often resulting in experimental variation. In the present study, TE SkM constructs were fabricated in a precision manufactured and commercially available polyether ether ketone (PEEK) 3D SkM TE culture chamber, and were compared to an 8-well 3D SkM TE culture chamber (8WC) model based on the attachment of the constructs to handmade "floatation bars" (Smith et al., 2012). Both SkM configurations have a similar rectangular geometry, but have variations in cellular volumes, chamber design, as well as the modes of attachment for the SkM construct (Figure 1). These variations enable the investigation of myotube parameters in contrasting systems, similar to those presented in the literature. Furthermore, by utilizing a precision manufactured and commercially available system such as the proposed PEEK chamber, it is foreseen that repeatability and replication of SkM constructs should be improved above the custom-built platform. Moreover, adopting an approach utilizing precision manufacturing would also facilitate movement toward scalable, higher-throughput systems. When seeking to evaluate the success of a given model, it is important to consider a number of myogenic parameters. Thus, it is necessary to examine the expression of key myogenic genes and the morphological characteristics of the seeded cells to assess the extent of differentiation. To this end, the purpose of this study was to understand the differences in basic myotube, myogenic mRNA and ECM characteristics when $\mathrm{C} 2 \mathrm{C} 12$ myoblasts were cultured in a previously published custom handmade system (8WC) compared with a precision manufactured configuration (PEEK).

\section{MATERIALS AND METHODS}

\section{Cell Culture}

C2C12 myoblasts (Public Health England sourced from ATCC) at passages 3-12 were maintained in basal Dulbecco's Modified Eagle's Medium (DMEM) (Sigma-Aldrich, United Kingdom) supplemented with $20 \% \mathrm{v} / \mathrm{v}$ fetal calf serum [First Link (UK) Ltd., United Kingdom] and 1\% v/v penicillin-streptomycin (Gibco Life Technologies, United Kingdom). All cell cultures were kept in a humidified incubator at $37^{\circ} \mathrm{C}$ and $5 \% \mathrm{CO}_{2}$ for the duration of the experiment.

\section{Chamber Configurations}

Constructs cultured in the 8WC (Figure 1) are setup in commercially available treated tissue culture plates Nunc $^{\mathrm{TM}}$, Thermo Fisher Scientific, United Kingdom), with the addition of polydimethylsiloxane (PDMS, Dow Corning, United States) walls to divide the chamber to the required dimensions for the polymerization process. The construct's attachment/anchor points are created from the attachment of three small rectangular layers of polyethylene mesh (Darice Inc., United States) stitched together by stainless steel wire $0.3 \mathrm{~mm}$ (Scientific Wire Company, United Kingdom). To generate a suitable anchor $0.5 \mathrm{~mm}$ hooped wire was bent over the edge of the side of the well. This meshed wire structure is known as the a-frame. The chamber dimensions are $14 \mathrm{~mm} \times 30 \mathrm{~mm} \times 10 \mathrm{~mm}$ and the volumetric capacity is $1.5 \mathrm{~mL}$. Manufactured chambers are fabricated from PEEK, a plastic that is biocompatible for use with cell cultures (Panayotov et al., 2016). The custom manufactured chamber has in-built cylindrical attachment/anchor points, that are posts set within the wells (Figure 1). The chamber dimensions are $10 \mathrm{~mm} \times 21.5 \mathrm{~mm} \times 5 \mathrm{~mm}$, and the volumetric capacity is $0.5 \mathrm{~mL}$ (Table 2). The PEEK chambers are precision machined, with final chamber geometries etched into the plastic, and are based on an outline similar to the CAD design in Figure 1C - PEEK. These PEEK chambers were designed to be used within standard 6-well plates. The PEEK chambers were kindly donated by Dr. James Phillips (University College London, United Kingdom).

\section{Cell Seeded Collagen Skeletal Muscle Constructs}

Type 1 rat tail collagen hydrogels were polymerized as previously described (Smith et al., 2012). The seeded collagen hydrogels were made to a measure of: $85 \% \mathrm{v} / \mathrm{v}$ type 1 rat tail collagen 
TABLE 1 | A comparison of commonly published skeletal muscle models.

\begin{tabular}{|c|c|c|c|c|c|c|}
\hline $\begin{array}{l}\text { Publication } \\
\text { features }\end{array}$ & $\begin{array}{l}\text { Vandenburgh et al., } \\
1996\end{array}$ & $\begin{array}{l}\text { Okano and } \\
\text { Matsuda, } 1998\end{array}$ & $\begin{array}{l}\text { Vandenburgh } \\
\text { et al., } 2008\end{array}$ & Chiron et al., 2012 & Smith et al., 2012 & Martin et al., 2015 \\
\hline \multicolumn{7}{|c|}{ Features of published skeletal muscle chambers } \\
\hline $\begin{array}{l}\text { Attachment/fixed } \\
\text { points }\end{array}$ & $\begin{array}{l}\text { Velcro and } \\
\text { stainless-steel pins }\end{array}$ & Fixed points & $\begin{array}{l}\text { Flexible silicone } \\
\text { posts }\end{array}$ & Silicone pins & Polyethylene mesh & Stainless-steel pins \\
\hline Construct volume & $400 \mu \mathrm{L}$ & $\mathrm{n} / \mathrm{a}$ & $100 \mu \mathrm{L}$ & $150 \mu \mathrm{L}$ & $3200 \mu \mathrm{L}$ & $700 \mu \mathrm{L}$ \\
\hline Matrix & $\begin{array}{l}\text { Collagen and } \\
\text { matrigel }{ }^{\circledR}\end{array}$ & Collagen & $\begin{array}{l}\text { Collagen, atrigel }{ }^{\oplus} \\
\text { and fibrin }\end{array}$ & Fibrin & Collagen & Thrombin and fibrin \\
\hline Matrices type & \multicolumn{6}{|c|}{ Natural } \\
\hline Seeded cell type & $\begin{array}{l}\text { C2C12 mouse } \\
\text { myoblasts }\end{array}$ & $\begin{array}{l}\mathrm{C} 2 \mathrm{C} 12 \text { mouse } \\
\text { myoblasts }\end{array}$ & $\begin{array}{l}\text { Primary mouse } \\
\text { myoblasts }\end{array}$ & Primary HDMCs & Primary rat DMCs & $\begin{array}{l}\text { C2C12 mouse } \\
\text { myoblasts or primary } \\
\text { human DMCs }\end{array}$ \\
\hline $\begin{array}{l}\text { Geometric } \\
\text { configuration of } \\
\text { chamber }\end{array}$ & Rectangular & $\begin{array}{l}\text { Mandrel - ring } \\
\text { shaped }\end{array}$ & Cylindrical & Rectangular & Rectangular & $\begin{array}{l}\text { Circular - then rolled } \\
\text { cylindrical tubes }\end{array}$ \\
\hline $\begin{array}{l}\text { Chamber design } \\
\text { type }\end{array}$ & Custom-built & Custom-built & Manufactured & Custom-built & Custom-built & Custom-built \\
\hline Chamber/well type & $\begin{array}{l}\text { Commercially } \\
\text { available silicone } \\
\text { tubing }\end{array}$ & Agarose gel ring & $\begin{array}{l}\text { Custom-built wells } \\
\text { with posts }\end{array}$ & Custom-built & $\begin{array}{l}\text { Commercially } \\
\text { available singular } \\
\text { rectangular wells }\end{array}$ & $\begin{array}{l}\text { Custom-built wells } \\
\text { with pins }\end{array}$ \\
\hline
\end{tabular}

The chambers used for 3D TE have three main corresponding features. (1) They are anchored by fixed point(s). (2) They have a geometric configuration that is rectangular. (3) The chambers are used with a natural (compliant) matrix. The hydrogel matrix/scaffold used for supporting cells varies between the models, as does construct volume, cell type, and seeding density per milliliter (latter not displayed).

[2.05 mg/mL; First Link (UK) Ltd., United Kingdom], 10\% of $10 \times$ minimal essential media (MEM; Gibco, United Kingdom), $5 \%$ v/v growth media (GM) containing $\mathrm{C} 2 \mathrm{C} 12 \mathrm{~s}$ at cellular density of $4 \times 10^{6}$ cells $/ \mathrm{mL}$. Prior to the addition of cells, the collagenMEM solution was neutralized by the drop-wise addition of sodium hydroxide (NaOH; Sigma-Aldrich, United Kingdom) at 5 and $1 \mathrm{M}$ aqueous concentrations. Neutralized acellular collagen solution remained on ice before and after the addition of C2C12s. The homogeneous mixed seeded constructs $(0.5 \mathrm{~mL}$ for PEEK chambers and $1.5 \mathrm{~mL}$ for $8 \mathrm{WC}$ model, respectively) were cast into the appropriate chambers and placed in a humidified incubator at $37^{\circ} \mathrm{C}$ and $5 \% \mathrm{CO}_{2}$ for $15 \mathrm{~min}$, to allow polymerization. Following polymerization, $6 \mathrm{~mL}$ of $\mathrm{GM}$ were added to each construct before returning to the incubator. GM was replenished daily, for a period of 4 days, at which point the medium was removed and replaced with differentiation medium (DM) consisting of DMEM supplemented with $2 \% \mathrm{v} / \mathrm{v}$ horse serum (Sigma-Aldrich, United Kingdom) and 1\% v/v penicillinstreptomycin (Gibco, United Kingdom). DM was replaced daily for the remaining 10 days of culture. Three replicates were created for each construct and six independent experimental repeats were conducted with a total " $n$ " number of constructs being 18 per chamber type; 12 for histochemistry and 6 for gene expression analysis.

\section{Fluorescent Staining}

Following 14 days in culture, the medium was removed from the wells of both configurations and constructs were fixed using $4 \%$ paraformaldehyde for a minimum of $60 \mathrm{~min}$. Subsequently, constructs were cut away from the attachment mesh and fixed points and washed three times with $1 \times$ Tris-buffered saline (TBS). Constructs were then submersed in $300 \mu \mathrm{L}$ of $0.2 \% \mathrm{v} / \mathrm{v}$ Triton X-100 (Fisher Scientific, United Kingdom) and diluted in TBS for $120 \mathrm{~min}$. Following three further washes with TBS, constructs were incubated overnight with rhodamine-phalloidin (Life Technologies, United Kingdom) diluted 1:200 $\mathrm{v} / \mathrm{v}$ in TBS. The following day, constructs were washed three times with TBS prior to incubation with $300 \mu \mathrm{L}$ of 4',6-diamidino-2-phenylindole (DAPI; Life Technologies, United Kingdom) diluted 1:2000 v/v in TBS for $10 \mathrm{~min}$. Following a final three washes with TBS, constructs were placed on polylysine-coated microscope slides (VWR, United Kingdom) and mounted to a coverslip using Fluoromount ${ }^{\mathrm{TM}}$ (SigmaAldrich, United Kingdom) mounting medium.

\section{Microscopic and Macroscopic Images}

Images of fluorescently stained TE SkM constructs were obtained using a confocal microscope (Zeiss LSM 880, Carl Zeiss, Germany) (Figure 2). Sets of 60 images were taken of myotubes within the constructs of each chamber type. Macroscopic images of whole constructs within their chambers (to assess macroscopic contraction) were taken throughout the duration of the experiment (Figure 2B). Images captured were taken using a digital camera (PEEK only) or a flatbed scanner (Epson V370) (8WC only).

\section{Image Analysis of Seeded Collagen Skeletal Muscle Construct}

All images (micro and macroscopic) were analyzed using FIJI Software by Image J (NIH, Bethesda, MD, United States) to collate the data for the different parameters required for the assessment of the two configurations. The following list 

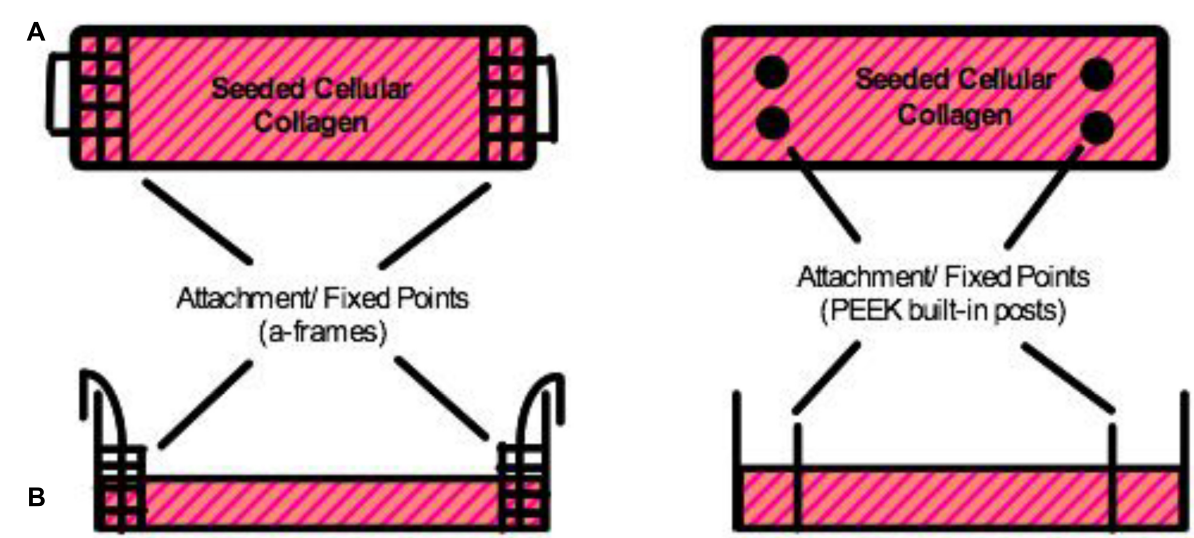

\section{8-Well Chamber}

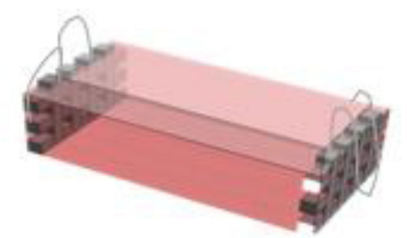

PEEK Chamber
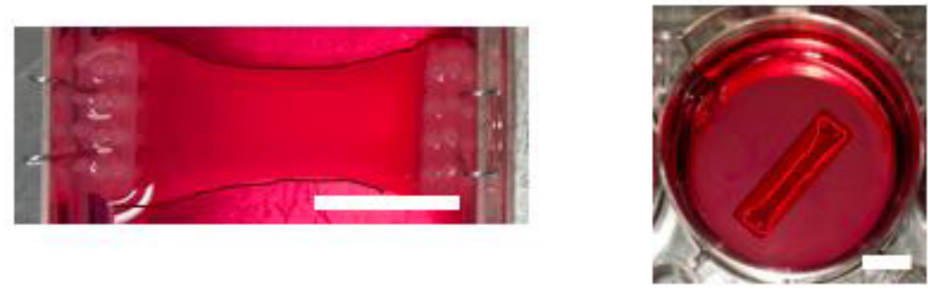

FIGURE 1 | Muscle chambers. (A) Schematic illustration of the muscle chambers with their respective attachment points. (B) CAD model of the respective chambers (images $\mathbf{A}$ and $\mathbf{B}$ are not to scale). (C) The 8WC and PEEK chambers used in our experimental research. The images have been enhanced by outlining the constructs to define their contrast within their chamber against the surrounding medium. Scale bars $=10 \mathrm{~mm}$.

TABLE 2 | Comparison of the chamber features used in this investigation to generate tissue engineered skeletal muscle.

\begin{tabular}{lll}
\hline \multicolumn{2}{l}{ 8-Well chamber } & PEEK chamber \\
\hline \multicolumn{2}{l}{ Muscle chamber features } & \\
Attachment/fixed points & $\begin{array}{l}\text { Polyethylene mesh } \\
\text { attachment }\end{array}$ & PEEK pins \\
Seeding conditions & Both $4 \times 10^{6}$ cells/mL of collagen used \\
Construct volume $(\mathrm{mL})$ & 1.5 & 0.5 \\
Geometric configuration & Rectangular & Rectangular \\
Design type & Custom-built & Commercially available - \\
& & precision manufactured \\
Well type & Tissue culture plastic - & PEEK wells with posts \\
rectangular 8-well & \\
Chamber cost & $£ 4.37$ per chamber & £99.60 per chamber \\
& & (autoclavable)
\end{tabular}

of measurements were obtained for each image: myotube width, myotube length, fusion index, number of myotubes, cell density, and the number of nuclei per myotube. Myotubes were classified as elongated structures containing three or more nuclei within a single membrane structure. Irregular mass, clumps, or multi-branched aggregation conformations (complex dysmorphic myotubes) with three or more nuclei were not counted as myotubes. Most myotubes were aligned to the uniaxial isometric lines of strain within the gel, however, some singular branched dysmorphic myotubes were counted. Myotube diameter was calculated as the average of 10 measurements along the myotube length (Rommel et al., 2001; Agley et al., 2012) for a representative measure. The fusion index was calculated as the number of nuclei incorporated into myotubes expressed as a percentage of the total number of nuclei in the image frame (Martin et al., 2015).

\section{RNA Extraction and RT-qPCR}

3D TE SkM constructs for both chamber types were detached from their anchor points and transferred to sterile $1.5 \mathrm{~mL}$ microcentrifuge tubes containing $500 \mu \mathrm{L}$ of TRI Reagent (Sigma-Aldrich, United Kingdom). The homogenization process (maximal shear) was achieved using a needle $(23 / 21 \mathrm{G})$ and syringe technique. RNA extraction was conducted according 


\section{Construct Deformation}

A

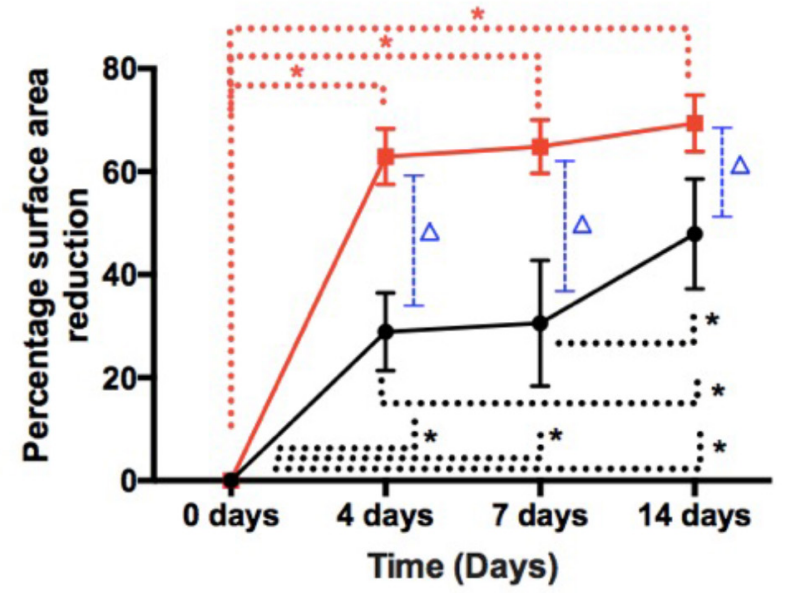

- 8-Well

PEEK

B

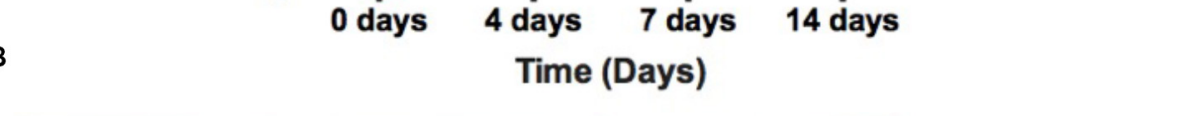

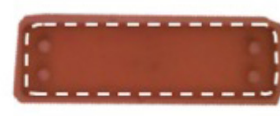

Day 0

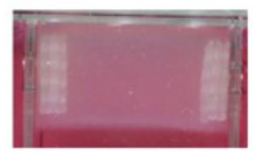

Day 0

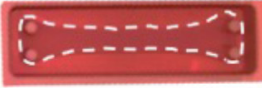

Day 4

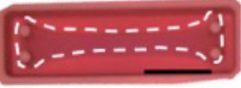

Day 7

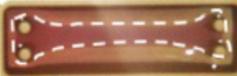

Day 14

\section{PEEK}

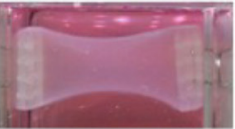

Day 4

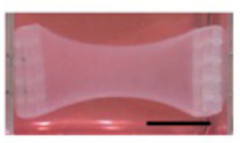

Day 7

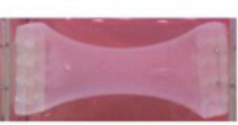

Day 14

\section{8-well}

\section{Construct Attachment Failure (day 14)}

C

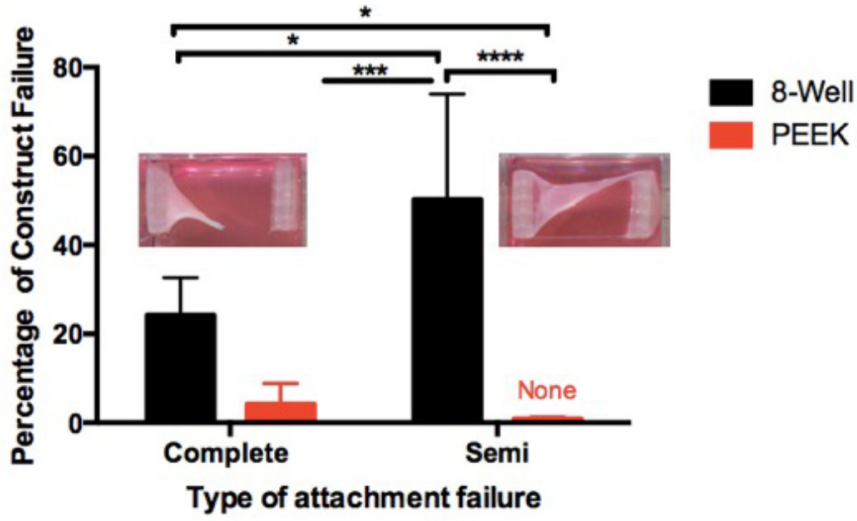

FIGURE 2 | Construct deformation (percentage of construct surface area reduction) over time (a maximum of 14 days) and percentage of attachment failure. (A) Construct deformation shows the area of construct reduction over the course of the experiment at key intervals (0, 4, 7 , and 14 days). The dotted lines with an asterisk show the link between the time intervals that have significance $(p$-value $<0.05)$ within the chamber type. The dotted line with a triangle $(p$-value $<0.0001)$ across the chamber types. (B) Macroscopic images of the constructs at days $0,4,7$, and 14 showing the constructs deformation over the course of the experimental time frame. The upper images are of PEEK constructs that have been enhanced by outlining the constructs to define their contrast within their chamber against the surrounding medium. The lower row images are of the 8WC. Scale bar $=10 \mathrm{~mm}$. (C) Attachment failure shows that 8 WC has the highest construct failure for both complete and semi-failure, and the image inserts depict attachment failures. For panel (C) significance at $* P<0.05,{ }^{* * *} P=0.0002,{ }^{* * * *} P<0.0001$.

to the TRI reagent manufacturer's instructions (SigmaAldrich, United Kingdom) using chloroform, 2-propanol and $70 \% \mathrm{v} / \mathrm{v}$ ethanol reagents (grade 200-proof, Sigma-Aldrich,
United Kingdom). RNA quality and quantity were measured by a NanoDrop 2000 spectrophotometer (Thermo Fisher Scientific, United Kingdom). Real-time quantitative polymerase chain 
TABLE 3 | Primer sequences used for detection of differentiation and extra-cellular matrix remodelling mRNA markers.

\begin{tabular}{|c|c|c|c|}
\hline Gene & Forward primer sequence & Reverse primer sequence & Function \\
\hline $\mathrm{RP} 2 \beta$ & GGTCAGAAGGGAACTTGTGGTAT & GCATCATTAAATGGAGTAGCGTC & Housekeeper \\
\hline Myogenin & CCAACTGAGATTGTCTGTC & GGTGTTAGCCTTATGTGAAT & Differentiation \\
\hline MMP-2 & GAGATCTTCTTCTTCAAGGAC & AATAGACCCAGTACTCATTCC & Matrix remodeling \\
\hline MMP-9 & CTGGCAGAGGCATACTTG & GCCGTAGAGACTGCTTCT & Matrix remodeling \\
\hline
\end{tabular}

reactions (RT-qPCRs) were prepared in triplicate in 348-well plates, where each well contained $20 \mathrm{ng}$ of RNA diluted in $5 \mu \mathrm{L}$ of RNase free water, $0.1 \mu \mathrm{L}$ of forward and reverse primers (Sigma-Aldrich, United Kingdom; see Table 3), $0.1 \mu \mathrm{L}$ of RT mix (Qiagen, Germany) and $4.7 \mu \mathrm{L}$ of SYBR green mix (Qiagen, Germany) to make $10 \mu \mathrm{L}$ total reaction volumes. One-step RT-qPCR was performed on a Viia7 ${ }^{\mathrm{TM}}$ Real-Time PCR system (Applied Biosystems/Thermo Fisher Scientific, United Kingdom), which was programed to perform the following: $10 \mathrm{~min}$ at $50^{\circ} \mathrm{C}$ (to enable reverse transcription), 5 min at $95^{\circ} \mathrm{C}$ (to activate "Hot Start" Taq polymerase), followed by 40 cycles of $95^{\circ} \mathrm{C}$ for $10 \mathrm{~s}$ and $60^{\circ} \mathrm{C}$ for $30 \mathrm{~s}$. Data was analyzed using the comparative $\mathrm{C}_{\mathrm{T}}$ otherwise known as the Livak method (Schmittgen and Livak, 2008) and relative gene expression $2^{\left(-\Delta \Delta C_{\mathrm{T}}\right)}$ method using RP2 $\beta$ as the reference gene. The muscle markers selected as primers (Table 3 ) were myogenin (MYOG) an indicator of myogenic differentiation and matrix metalloproteinases (MMPs)-2 and -9 as indicators of matrix remodeling.

\section{Statistical Analysis}

All data sets are presented as the mean value \pm standard deviation per condition on day 14 . Normality tests were conducted to evaluate the distribution of the data. $t$-Tests were conducted for myotube analysis tests and (factorial) two-way ANOVA for construct deformation; both tests were used to determine if statistical differences existed between the two different construct chambers. $t$-Tests were conducted using GraphPad Prism software V6 (GraphPad Software Inc., United States). Factorial ANOVA was conducted using IBM SPSS version 23 (International Business Machines Corp., United States). Significance was set at an alpha value of $p \leq 0.05$.

\section{RESULTS}

\section{Construct Deformation and Failure Rates}

Construct area reduction (deformation) was measured over the experimental duration of 14 days (Figure 2). Morphologically, the percentage area of reduction for the $8 \mathrm{WC}$ and PEEK constructs increased over time (4 days: $28.89 \pm 7.55 \% 8 \mathrm{WC}$ vs. $62.88 \pm 5.44 \%$ PEEK, $p$-value $<0.0001 ; 7$ days: $30.57 \pm 12.17 \%$ $8 \mathrm{WC}$ vs. $64.86 \pm 5.25 \%$ PEEK, $p$-value < 0.0001; 14 days: $47.87 \pm 10.70 \% 8 \mathrm{WC}$ vs. $69.39 \pm 5.50 \%$ PEEK, $p$-value $<0.0001)$. This demonstrates, that mean percentage deformation (reduction in area) is greater in the PEEK than $8 \mathrm{WC}$ at all time points analyzed (excluding day 0). Interestingly, the 8WC constructs failed to reach $50 \%$ deformation by end the end of the experiment, which may well be a result of differences in construct volume and total cell number compared to the PEEK system. Figure 2C highlights the failure rates for both $8 \mathrm{WC}$ and PEEK constructs. It was noticed that PEEK constructs only failed within the first $24 \mathrm{~h}$ due to failed attachment to the posts. Complete failure (total detachment from anchor posts) and partial detachment was more frequent for the $8 \mathrm{WC}$ than for the PEEK, suggesting collagen attachment and remodeling is different between systems. Complete and semi-failure rates, reported significant differences between chamber types (Figure 2, semi-failure: $50.21 \pm 23.74 \%$ $8 \mathrm{WC}$ vs. $0 \%$ PEEK, $p<0.0001$, complete failure: $24.2 \pm 8.44 \%$ $8 \mathrm{WC}$ vs. $4.20 \pm 4.60 \%$ PEEK, $p=0.05)$. This large variability in failure rates highlights the difficulty in reliability and handling of the custom-built chamber and its construct, respectively.

\section{Morphological Parameters of $\mathrm{C}_{2} \mathrm{C} 12$ Myotubes Within 3D Tissue-Engineered Constructs in Different Chamber Configurations}

To determine the overall level of morphological differentiation (and variable differences), myotube parameters (myotube; width, length, number, number of nuclei per myotube, and fusion index) were measured based on fluorescence imaging of the actin cytoskeleton (Figure 3 ). This allowed a detailed comparison between both systems to be made (Table 4). Myotube parameters for the $8 \mathrm{WC}$ model were found to be generally higher (increases in mean values), compared to the PEEK chamber. However, no statistical differences were noted for any measures (all $p>0.05)$, indicating that the morphological outcomes were reproducible between both chamber types. This suggests that

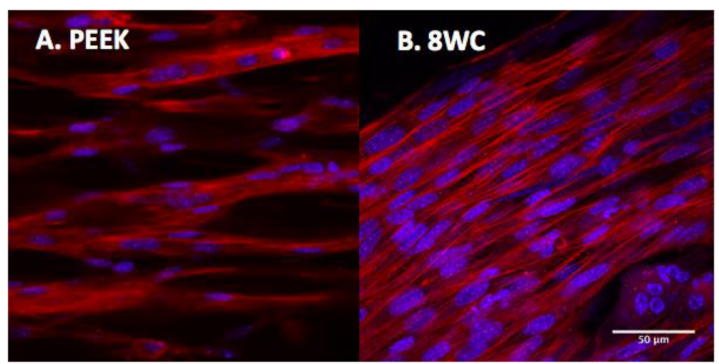

FIGURE 3 | C2C12 myotubes within collagen matrix of 3D tissue-engineered constructs. Confocal images at 14 days. Histochemical staining with rhodamine-phalloidin (actin filaments in red). Cells nuclei are counterstained with 4',6-diamidino-2-phenylindole (DAPI; nuclei in blue). (A) PEEK constructs and (B) 8-well constructs. Scale bars at $50 \mu \mathrm{m}$. 
TABLE 4 | Parameters used to assess morphological difference after 14 days in culture.

\begin{tabular}{lccc}
\hline & 8-Well chamber & PEEK chamber & $\boldsymbol{p}$-values \\
\hline $\begin{array}{l}\text { Morphological measures } \\
\text { Myotube width }(\mu \mathrm{m})\end{array}$ & $14.32 \pm 2.10$ & $14.00 \pm 2.75$ & 0.9949 \\
$\begin{array}{l}\text { Myotube length* }(\mu \mathrm{m}) \\
\text { Number of myotubes }\end{array}$ & $172.10 \pm 18.35$ & $165.9 \pm 11.82$ & 0.9672 \\
(au) & $25.00 \pm 8.74$ & $21.17 \pm 8.23$ & 0.8109 \\
$\begin{array}{l}\text { Number of nuclei per } \\
\text { myotube (au) }\end{array}$ & $6.818 \pm 1.32$ & $8.770 \pm 2.03$ & 0.1000 \\
$\begin{array}{l}\text { Cell density (au) } \\
\text { Fusion index (\%) }\end{array}$ & $139.0 \pm 26.45$ & $124.6 \pm 28.34$ & 0.6611 \\
$\begin{array}{l}\text { Distance between } \\
\text { myotubes }(\mu \mathrm{m})\end{array}$ & $14.93 \pm 6.94$ & $52.87 \pm 2.96$ & $>0.9999$ \\
$\begin{array}{l}\text { Number of myotube } \\
\text { branches (au) }\end{array}$ & $3.17 \pm 1.83$ & $8.63 \pm 2.58$ & 0.414 \\
& & & \\
\end{tabular}

Mean measures of the myotube parameters and their units from their respective constructs (chamber type). Au, arbitrary units. *Due to limitation of the image frame myotube length measurements are possibly greater than that measured.

despite differences in volumes, dimensions, and anchor types between chamber types, the degree to which myotubes form at a given seeding density may be limited.

\section{mRNA Expression Levels for Differentiation and Remodeling Matrix Markers at Day 14}

Myogenic gene expression markers are indicators which can be used to gain insight into the progress of these early SkM cells (myoblasts) toward cellular differentiation (Bentzinger et al., 2012). Levels of mRNA expression for differentiation (MYOG) and ECM remodeling markers (MMP-2 and -9), were compared between the PEEK chamber and 8WC (Figure 4). There were no significant differences between the two chambers for all genes measured, with similar $p$-values (all $p>0.99$ ), supporting the morphological outcomes described above, and a trend toward biological reproducibility within the model irrespective of tissue chamber manufacturing method.

\section{DISCUSSION}

TE of $3 \mathrm{D} \mathrm{SkM}$ is based on the developmental biology and regeneration of native tissue, i.e., the ability of myogenic precursors to activate, proliferate, and differentiate into multinucleated myotubes in 3D (Okano and Matsuda, 1997, 1998; Okano et al., 1997). Consequently, many SkM models (Table 1) display three common features: (i) high cellular density (Khodabukus et al., 2007; Mudera et al., 2010); (ii) the ECM/scaffold used (Bian and Bursac, 2008, 2009); and (iii) the presence of fixed points within the chamber facilitating uniaxial (isometric) tension enabling cellular alignment (Table 1). Despite these commonalities, the bespoke nature of these published models means there are many differences in the basic configuration; shape, volume, attachment type, etc.

Here, a comparison between two contrasting systems was made in order to determine differences in myotube parameters. Assessment of fluorescence micrographs of the PEEK chamber vs. $8 \mathrm{WC}$, clearly shows similar myotube morphology, with singular unbranched myotubes regardless of the configuration used (Table 4). This response confirms previous publication by this research group, in larger scale models using the similar chamber materials (5 and $3 \mathrm{~mL}$; Sharples et al., 2012; Smith et al., 2012; Player et al., 2014).

Myogenin has been extensively reported to be a late marker of myoblast fusion, required for terminal differentiation (Tan et al., 2015). Mudera et al. (2010) and Smith et al. (2012) demonstrated the expression pattern of MYOG in similar tissue engineered models, where comparisons were made against $2 \mathrm{D}$ controls. It was suggested that myotube formation was supported by the extent of MYOG expression (Mudera et al., 2010; Smith et al., 2012), which supports the results reported herein. The expression of MYOG mRNA, showed no difference between configurations tested, suggesting the molecular regulation of differentiation is not altered between conditions.

The similarity in myotube formation also highlights the importance of isometric and uniaxial strain providing ECM cues for directional signaling, independent of anchor type and attachment structure. Cellular attachment, alignment, and ECM remodeling contributes to macroscopic characteristic deformation (Sharples et al., 2012; Smith et al., 2012), causing loss of interstitial fluid (Phillips, 2014). Subsequently, an increase in relative cell density contributes to an increase in cell-cell contact promoting fusion. Despite this, clear differences in construct deformation were found between chamber types. This data contrasts previous observations of ECM remodeling gene expression, where no differences were observed in either MMP-2 or -9 mRNA, which may reflect the post-translational function
A

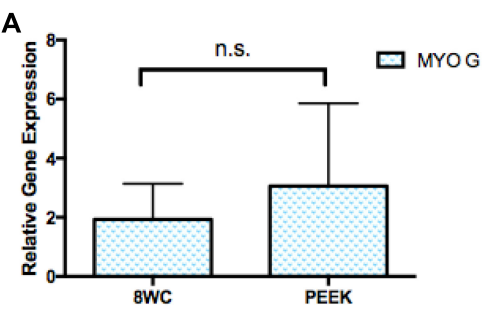

B

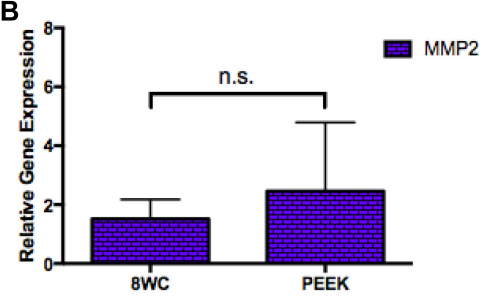

C

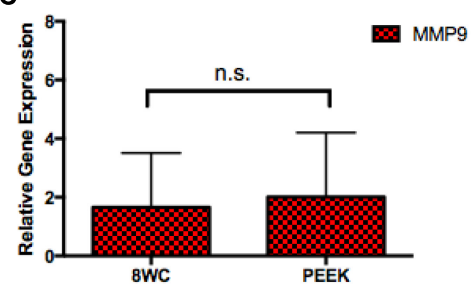

FIGURE 4 | mRNA expression levels for differentiation and remodeling matrix markers. Gene expression at day 14 for (A) MYOG, (B) MMP-2, and (C) MMP-9. No significance difference (n.s.), $p$-values all measured $>0.99$. 
of these proteins. Indeed, it may well be that within a given configuration (where finite mechanical signals are different) there is a limit in the extent to which matrix remodeling contributes to myotube formation and may also reflect differences at macroscopic and molecular levels.

Attachment failure in both its forms (complete and semi) was more prevalent in the $8 \mathrm{WC}$ compared to the PEEK. An overview of the morphological parameters of the constructs from both chamber types, also shows that the PEEK constructs have reduced variability (standard deviation) than $8 \mathrm{WC}$ constructs (number of nuclei per myotube, being the exception). Indeed, variability within custom made systems has previously been noted in engineered muscle (Brady et al., 2008; Mudera et al., 2010) and therefore the present results indicate that a precision manufactured PEEK system could lead to improved and more standardized results.

The custom, handmade $8 \mathrm{WC}$ produces variation and inconsistencies, both in assembly between researchers and positioning within the chamber. As such, it is likely that this will have a marked effect as to how the constructs attach and develop. By utilizing a commercially available PEEK chamber, consistency and reliability are achieved with this system, particularly as the chambers can be autoclaved and reused. This consistency and reliability becomes more critical when using primary cells types which are difficult to derive, isolate, and culture. Furthermore, this precision manufacturing facilitates the use of automation techniques, which will be a key asset for applications requiring higher-throughput (Vandenburgh, 2010; Nam et al., 2015).

\section{CONCLUSION}

In this study, 3D TE SkM constructs were fabricated using both commercially available PEEK and custom-built 8WC.

\section{REFERENCES}

Agley, C. C., Velloso, C. P., Lazarus, N. R., and Harridge, S. D. (2012). An image analysis method for the precise selection and quantitation of fluorescently labeled cellular constituents: application to the measurement of human muscle cells in culture. J. Histochem. Cytochem. 60, 428-438. doi: 10.1369/ 0022155412442897

Bentzinger, C. F., Wang, Y. X., and Rudnicki, M. A. (2012). Building muscle: molecular regulation of myogenesis. Cold Spring Harb. Perspect. Biol. 4:a008342. doi: 10.1101/cshperspect.a008342

Bian, W., and Bursac, N. (2008). Tissue engineering of functional skeletal muscle: challenges and recent advances. IEEE Eng. Med. Biol. Mag. 27, 109-113.

Bian, W. N., and Bursac, N. (2009). Engineered skeletal muscle tissue networks with controllable architecture. Biomaterials 30, 1401-1412. doi: 10.1016/j. biomaterials.2008.11.015

Brady, M. A., Lewis, M. P., and Mudera, V. (2008). Synergy between myogenic and non-myogenic cells in a 3D tissue-engineered craniofacial skeletal muscle construct. J. Tissue Eng. Regen. Med. 2, 408-417. doi: 10.1002/term.112

Cen, L., Liu, W., Cui, L., Zhang, W., and Cao, Y. (2008). Collagen tissue engineering: development of novel biomaterials and applications. Pediatr. Res. 63, 492-496. doi: 10.1203/PDR.0b013e31816c5bc3

Cheema, U., Brown, R., Mudera, V., Yang, S. Y., Mcgrouther, G., and Goldspink, G. (2005). Mechanical signals and IGF-I gene splicing In vitro in relation to
Engineered muscle fabricated using PEEK and 8WC were comparable in myotube morphology and mRNA expression, however, the collagen matrix in PEEK constructs deformed and remodeled faster than in the 8WC setup. Importantly, however, the variables measured showed less variability in PEEK configurations compared to 8WC, and displayed dramatically reduced experimental failure rates. The PEEK chamber offers a consistent and reliable system to engineer SkM, however, with no apparent differences in the myotubes that are produced, the resource and particularly the application should be considered when selecting chamber type.

\section{AUTHOR CONTRIBUTIONS}

JJ conducted the experiments. DP, AC, and NM contributed to experimental work and manuscript editing. $\mathrm{VM}$ and $\mathrm{ML}$ conducted the final editing and proof reading as well as project supervision.

\section{FUNDING}

Many thanks to the E.U. Framework 7 BIODESIGN programme for providing financial support to this project (Biodesign Grant Award No: 262948).

\section{ACKNOWLEDGMENTS}

Sincere gratitude to UCL's late Professor Robert Brown, who envisaged this work as part of the BioDesign Network. Thanks also to Dr. James Phillips (UCL) for his assistance in obtaining the PEEK chambers and to Mr. Tim Self (University of Nottingham) for imaging support.

development of skeletal muscle. J. Cell. Physiol. 202, 67-75. doi: 10.1002/jcp. 20107

Cheema, U., Yang, S. Y., Mudera, V., Goldspink, G. G., and Brown, R. A. (2003). 3-D In vitro model of early skeletal muscle development. Cell Motil. Cytoskeleton 54, 226-236. doi: 10.1002/cm.10095

Chiron, S., Tomczak, C., Duperray, A., Laine, J., Bonne, G., Eder, A., et al. (2012). Complex interactions between human myoblasts and the surrounding 3D fibrin-based matrix. PLoS One 7:e36173. doi: 10.1371/journal.pone. 0036173

Dennis, R. G., and Kosnik, P. E. (2000). Excitability and isometric contractile properties of mammalian skeletal muscle constructs engineered in vitro. In Vitro Cell. Dev. Biol. Anim. 36, 327-335. doi: 10.1290/1071-2690(2000) 036<0327:EAICPO>2.0.CO;2

Eastwood, M., Porter, R., Khan, U., Mcgrouther, G., and Brown, R. (1996). Quantitative analysis of collagen gel contractile forces generated by dermal fibroblasts and the relationship to cell morphology. J. Cell. Physiol. 166, 33-42. doi: 10.1002/(SICI)1097-4652(199601)166:1<33::AID-JCP4>3.0.CO;2-H

Gillies, A. R., and Lieber, R. L. (2011). Structure and function of the skeletal muscle extracellular matrix. Muscle Nerve 44, 318-331. doi: 10.1002/mus.22094

Hodgson, D. (2015). Modelling Muscles In vitro: A Finite Element Analysis Study. Master thesis, University College London Depository, London.

Huang, Y. C., Dennis, R. G., Larkin, L., and Baar, K. (2005). Rapid formation of functional muscle In vitro using fibrin gels. J. Appl. Physiol. 98, 706-713. doi: 10.1152/japplphysiol.00273.2004 
Ito, A., Yamamoto, Y., Sato, M., Ikeda, K., Yamamoto, M., Fujita, H., et al. (2014). Induction of functional tissue-engineered skeletal muscle constructs by defined electrical stimulation. Sci. Rep. 4:4781. doi: 10.1038/srep04781

Khodabukus, A., and Baar, K. (2009). Regulating fibrinolysis to engineer skeletal muscle from the C2C12 cell line. Tissue Eng. Part C Methods 15, 501-511. doi: 10.1089/ten.TEC.2008.0286

Khodabukus, A., and Baar, K. (2015). Factors that affect tissue-engineered skeletal muscle function and physiology. Cells Tissues Organs 202, 159-168. doi: 10.1159/000446067

Khodabukus, A., Paxton, J. Z., Donnelly, K., and Baar, K. (2007). Engineered muscle: a tool for studying muscle physiology and function. Exerc. Sport Sci. Rev. 35, 186-191. doi: 10.1097/jes.0b013e318156df01

Martin, N. R., Passey, S. L., Player, D. J., Mudera, V., Baar, K., Greensmith, L., et al. (2015). Neuromuscular junction formation in tissue-engineered skeletal muscle augments contractile function and improves cytoskeletal organization. Tissue Eng. Part A 21, 2595-2604. doi: 10.1089/ten.TEA.2015. 0146

Mohanty, S., Larsen, L. B., Trifol, J., Szabo, P., Burri, H. V. R., Canali, C., et al. (2015). Fabrication of scalable and structured tissue engineering scaffolds using water dissolvable sacrificial 3D printed chambers. Mater. Sci. Eng. C Mater. Biol. Appl. 55, 569-578. doi: 10.1016/j.msec.2015.06.002

Morimoto, Y., Kato-Negishi, M., Onoe, H., and Takeuchi, S. (2013). Threedimensional neuron-muscle constructs with neuromuscular junctions. Biomaterials 34, 9413-9419. doi: 10.1016/j.biomaterials.2013.08.062

Mudera, V., Smith, A. S., Brady, M. A., and Lewis, M. P. (2010). The effect of cell density on the maturation and contractile ability of muscle derived cells in a $3 \mathrm{D}$ tissue-engineered skeletal muscle model and determination of the cellular and mechanical stimuli required for the synthesis of a postural phenotype. J. Cell. Physiol. 225, 646-653. doi: 10.1002/jcp.22271

Nam, K. H., Smith, A. S., Lone, S., Kwon, S., and Kim, D. H. (2015). Biomimetic $3 \mathrm{D}$ tissue models for advanced high-throughput drug screening. J. Lab. Autom. 20, 201-215. doi: 10.1177/2211068214557813

Okano, T., and Matsuda, T. (1997). Hybrid muscular tissues: preparation of skeletal muscle cell-incorporated collagen gels. Cell Transplant. 6, 109-118. doi: 10.1177/096368979700600204

Okano, T., and Matsuda, T. (1998). Tissue engineered skeletal muscle: preparation of highly dense, highly oriented hybrid muscular tissues. Cell Transplant. 7, 71-82. doi: 10.1177/096368979800700110

Okano, T., Satoh, S., Oka, T., and Matsuda, T. (1997). Tissue engineering of skeletal muscle. Highly dense, highly oriented hybrid muscular tissues biomimicking native tissues. Asaio J. 43, M749-M753. doi: 10.1097/00002480-19970300000060

Ostrovidov, S., Ahadian, S., Ramon-Azcon, J., Hosseini, V., Fujie, T., Parthiban, S. P., et al. (2014). Three-dimensional co-culture of C2C12/PC12 cells improves skeletal muscle tissue formation and function. J. Tissue Eng. Regen. Med. 11, 582-595. doi: 10.1002/term.1956

Panayotov, I. V., Orti, V., Cuisinier, F., and Yachouh, J. (2016). Polyetheretherketone (PEEK) for medical applications. J. Mater. Sci. Mater. Med. 27:118. doi: 10.1007/s10856-016-5731-4

Perniconi, B., and Coletti, D. (2014). Skeletal muscle tissue engineering: best bet or black beast? Front. Physiol. 5:255. doi: 10.3389/fphys.2014.00255

Phillips, J. B. (2014). Building stable anisotropic tissues using cellular collagen gels. Organogenesis 10, 6-8. doi: 10.4161/org.27487

Player, D. J., Martin, N. R., Passey, S. L., Sharples, A. P., Mudera, V., and Lewis, M. P. (2014). Acute mechanical overload increases IGF-I and MMP-9 mRNA in 3D tissue-engineered skeletal muscle. Biotechnol. Lett. 36, 1113-1124. doi: 10.1007/s10529-014-1464-y
Powell, C. A., Smiley, B. L., Mills, J., and Vandenburgh, H. H. (2002). Mechanical stimulation improves tissue-engineered human skeletal muscle. Am. J. Physiol. Cell Physiol. 283, C1557-C1565. doi: 10.1152/ajpcell.00595.2001

Riboldi, S. A., Sadr, N., Pigini, L., Neuenschwander, P., Simonet, M., Mognol, P., et al. (2008). Skeletal myogenesis on highly orientated microfibrous polyesterurethane scaffolds. J. Biomed. Mater. Res. A 84, 1094-1101. doi: 10.1002/jbm.a.31534

Rommel, C., Bodine, S. C., Clarke, B. A., Rossman, R., Nunez, L., Stitt, T. N., et al. (2001). Mediation of IGF-1-induced skeletal myotube hypertrophy by $\mathrm{PI}(3) \mathrm{K} / \mathrm{Akt} / \mathrm{mTOR}$ and $\mathrm{PI}(3) \mathrm{K} / \mathrm{Akt} / \mathrm{GSK} 3$ pathways. Nat. Cell Biol. 3, 1009-1013. doi: 10.1038/ncb1101-1009

Sakar, M. S., Neal, D., Boudou, T., Borochin, M. A., Li, Y., Weiss, R., et al. (2012). Formation and optogenetic control of engineered 3D skeletal muscle bioactuators. Lab Chip 12, 4976-4985. doi: 10.1039/c2lc40338b

Schmittgen, T. D., and Livak, K. J. (2008). Analyzing real-time PCR data by the comparative C(T) method. Nat. Protoc. 3, 1101-1108. doi: 10.1038/nprot. 2008.73

Sharples, A. P., Player, D. J., Martin, N. R., Mudera, V., Stewart, C. E., and Lewis, M. P. (2012). Modelling in vivo skeletal muscle ageing In vitro using threedimensional bioengineered constructs. Aging Cell 11, 986-995. doi: 10.1111/j. 1474-9726.2012.00869.x

Smith, A. S., Passey, S., Greensmith, L., Mudera, V., and Lewis, M. P. (2012). Characterization and optimization of a simple, repeatable system for the long term In vitro culture of aligned myotubes in 3D. J. Cell. Biochem. 113, 1044-1053. doi: 10.1002/jcb.23437

Smith, A. S., Passey, S. L., Martin, N. R., Player, D. J., Mudera, V., Greensmith, L., et al. (2016). Creating interactions between tissue-engineered skeletal muscle and the peripheral nervous system. Cells Tissues Organs 202, 143-158. doi: 10.1159/000443634

Snyman, C., Goetsch, K. P., Myburgh, K. H., and Niesler, C. U. (2013). Simple silicone chamber system for In vitro three-dimensional skeletal muscle tissue formation. Front. Physiol. 4:349. doi: 10.3389/fphys.2013.00349

Tan, S. J., Fang, J. Y., Wu, Y., Yang, Z., Liang, G., and Han, B. (2015). Muscle tissue engineering and regeneration through epigenetic reprogramming and scaffold manipulation. Sci. Rep. 5:16333. doi: 10.1038/srep16333

Vandenburgh, H. (2010). High-content drug screening with engineered musculoskeletal tissues. Tissue Eng. Part B Rev. 16, 55-64. doi: 10.1089/ten.TEB.2009.0445

Vandenburgh, H., Del Tatto, M., Shansky, J., Lemaire, J., Chang, A., Payumo, F., et al. (1996). Tissue-engineered skeletal muscle organoids for reversible gene therapy. Hum. Gene Ther. 7, 2195-2200. doi: 10.1089/hum.1996.7. 17-2195

Vandenburgh, H., Shansky, J., Benesch-Lee, F., Barbata, V., Reid, J., Thorrez, L., et al. (2008). Drug-screening platform based on the contractility of tissueengineered muscle. Muscle Nerve 37, 438-447. doi: 10.1002/mus.20931

Conflict of Interest Statement: The authors declare that the research was conducted in the absence of any commercial or financial relationships that could be construed as a potential conflict of interest.

Copyright (C) 2018 Jones, Player, Martin, Capel, Lewis and Mudera. This is an openaccess article distributed under the terms of the Creative Commons Attribution License (CC BY). The use, distribution or reproduction in other forums is permitted, provided the original author(s) and the copyright owner are credited and that the original publication in this journal is cited, in accordance with accepted academic practice. No use, distribution or reproduction is permitted which does not comply with these terms. 